\title{
PERAN KELUARGA DALAM PENINGKATAN KEMAMPUAN INTERAKSI \\ SOSIAL BERMASYARAKAT KLIEN SKIZOFRENIA PASCA PERAWATAN DI RUMAH SAKIT
}

\author{
Lailatul Maghfiroh*, Khamida** \\ Fakultas Keperawatan dan Kebidanan \\ Universitas Nahdlatul Ulama Surabaya \\ Email: khamida@unusa.ac.id
}

\section{ABSTRACT}

Family has a strategic function for the schizophrenic client's social interaction, the role of family really needs to reached client independent, The role of family enables the schizophrenic individual to re-adapt the social life in the society. This research destination to analyze realiontship the family role and the Scizophrenic client's interaction level in the social life.

This research applied the analytic cross sectional design. The populations of the research were the schizophrenic clients who have been hospitalized and left the RSJ Menur Surabaya (Surabaya Menur Mental Hospital) and their family who lived in Surabaya moreless 30 respondens with samples taken by using the total population method involved 28 repondents. For independent variable the family role anddependent variable is level interaction society. The data were collected by filling out the checklist, doing observations and interviews which were then analyzed by using the SPSS and the Rank Spearman statistical test with the significance level $p<0,05$.

The result of the research showed that the family role contributed the family role was shown by 12 respondents $(42,8 \%)$. The schizophrenic clients social interaction level sufficiently was shown by 14 respondents (50\%). The statiscal test revealed the result that $p<0,05=0,10<0,05$ so that Ho was can't accepted.

This research concluded that there was a relationship between the family role and the schizophrenic clients social interaction level in the social life posttreatment in RSJ Menur Surabaya. So that, the staff of hospital give role every room at RSJ Menur Surabaya (Surabaya Menur Mental Hospital) the family need to direct follow for Schizoprenic client's in cure at RSJ Menur and for nurse advice to family give maximal attention.

Keywords : role, social interaction, schizophrenic.

\section{ABSTRAK}

Keluarga memiliki fungsi strategis dalam interaksi sosial klien Skizofrenia, peran keluarga sangatlah diperlukan dalam memenuhi kemandirian klien, adanya peran keluarga memungkinkan klien bisa beradaptasi ke 
masyarakat. Penelitian ini bertujuan menganalisis hubungan peran keluarga terhadap tingkat interaksi sosial bermasyarakat pada klien Skizofrenia.

Desain penelitian ini adalah analitik dengan jenis rancangan cross sectional. Populasi penelitian ini adalah klien Skizofrenia yang keluar dari RSJ Menur dan keluarga klien yang tinggal di Surabaya sebesar 30 responden dengan sampel 28 responden dengan metode simpel random sampling. Untuk variabel independent adalah peran keluarga dan variabel dependent adalah tingkat interaksi sosial bermasyarakat. Pengumpulan data dengan pengisian check list, observasi, wawancara dan dianalisis menggunakan SPSS uji statistik Rank Spearman pada tingkat kemaknaan $<0,05$.

Hasil penelitian peran keluarga didapat hasil cukup, sebanyak 12 reponden $(42,8 \%)$. Tingkat interaksi sosial klien Skizofrenia didapat hasil cukup sebanyak 14 responden(50\%). Hasil uji statistik didapatkan bahwa p $<0,05=0,10$ $<0,05$ maka Ho ditolak.

Simpulan dari penelitian adalah ada hubungan antara peran keluarga dengan tingkat interaksi sosial bermasyarakat pada klien Skizofrenia. Untuk itu sebaiknya pihak RS menetapkan setiap ruangan di RSJ Menur, keluarga perlu dilibatkan secara langsung kepada klien Skizofrenia selama perawatan di RS. Dan bagi perawat agar menerapkan pemeberian terapi keluarga secara maksimal.

Kata kunci : Peran, Interaksi, Skizofrenia

\section{PENDAHULUAN}

Skizofrenia adalah kelainan-kelainan yang berhubungan dengan psikosis yang terdiri dari suatu kelompok sindrom klinis yang dinyatakan dengan kelainan dalam isi organisasi pikir, interpretasi masukan sensori, ketegangan afek atau emosional, identitas kemauan, perilaku psikomotor, dan kemampuan untuk menetapkan hubungan interpersonal yang memuaskan.

Skizofrenia bisa terjadi pada siapa saja. Seringkali pasien Skizofrenia digambarkan sebagai individu yang bodoh, aneh, dan berbahaya. Sebagai konsekuensi kepercayaan tersebut, banyak pasien Skizofrenia tidak dibawa berobat ke dokter (psikiater) melainkan disembunyikan, kalaupun akan dibawa berobat, mereka tidak dibawa ke dokter melainkan dibawa ke "orang pintar". Selain itu juga untuk menghilangkan stigma pada keluarga dan masyarakat terhadap gangguan jiwa Skizofrenia ini, maka berbagai upaya penyuluhan dan sosialisasi gangguan jiwa Skizofrenia perlu diberikan.

Pada kenyataan yang ada di Rumah Sakit Jiwa, banyak klien yang jarang dikunjungi keluarga, akibatnya keluarga tidak mengikuti proses perawatan klien dan kesan yang ada pada keluarga hanyalah perilaku klien sewaktu dibawa ke Rumah Sakit. Di pihak lain, di RSJ Menur terutama di kelas III, memiliki aturan bahwa pasien tidak boleh ditunggu oleh keluarganya, sehingga membuat peran keluarga 
terhadap pasien sangat tidak maksimal. Sebelum pasien dipulangkan ke rumah, pasien telah dipersiapkan terlebih dahulu, seperti terapi-terapi yang telah diberikan untuk mempersiapkan pasien kembali ke lingkungan masyarakat. Setelah sembuh, pihak Rumah Sakit memulangkan klien ke lingkungan keluarga. Sekembalinya dari rumah sakit, pasien adalah bagian dari masyarakat yang berkewajiban menjalankan interaksi sosialnya. Pemulangan pasien Skizofrenia pada keluarga tergantung pada keparahan penyakit dan tersedianya fasilitas pengobatan rawat jalan. Keadaan pasien yang membaik dilanjutkan dengan rawat jalan. Ironisnya, pemulangan pasien Skizofrenia pada keluarga menimbulkan permasalahan yang baru, seperti klien selama di rumah dilarang keluar kamar dan gerakgerik klien diawasi dengan sikap curiga, sedangkan di dalam kehidupan masyarakat klien cenderung diam, mau berbicara apabila diajak bicara oleh orang lain. Meskipun klien diperolok, klien tetap diam saja, hal ini dikhawatirkan klien akan kambuh karena merasa ditekan oleh lingkungan sekitar. Keadaan ini merupakan proses adaptasi klien terhadap lingkungan yang kaku dan stimulus yang kurang (Kaplan dan Sadock, 2001)

Klien skizofrenia Sebagian besar $(75 \%)$ mulai mengidapnya pada usia 16-25 tahun. Usia remaja dan dewasa muda memang berisiko tinggi karena tahap kehidupan ini penuh stressor. Penyebab dari gangguan interaksi sosial bermasyarakat pada klien skizofrrenia ditimbulkan karena adanya stressor psikososial (setiap keadaan atau peristiwa yang menyebabkan perubahan dalam kehidupan seseorang) sehingga orang tersebut terpaksa menyesuaikan diri (adaptasi) untuk menanggulangi stressor (tekanan mental) yang timbul, namun tidak semua orang mampu melakukan adaptasi dan mampu menanggulangi sehingga timbullah keluhan-keluhan kejiwaan. Adapun faktor-faktor yang menyebabkan gangguan interaksi sosial klien adalah gangguan hubungan interpersonal, lingkungan hidup yang dapat menjadi stressor.

Setiap tahun terdapat 300.000 klien Skizofrenia mengalami episode akut, setiap tahunnya $35 \%$ klien skizofrenia mengalami kekambuhan (Hawari:2005). Penelitian yang dilakukan oleh Russel Barton menyatakan bahwa $50 \%$ dari penderita Skizofrenia kronis yang mengalami program rehabilitasi dapat kembali produktif dan mampu menyesuaikan diri kembali di keluarga dan masyarakat (Hawari, 2005)..

Terapi klien Skizofrenia
dilakukan dengan holistik, yang diharapkan klien dapat kembali berinteraksi sosial secara wajar dalam kehidupan sehari-hari baik di rumah, di sekolah atau kampus, di tempat kerja dan lingkungan sosial (masyarakat). Setelah klien mempunyai kemampuan dan ketrampilan, maka klien dapat mengikuti program pulang bertahap.

Klien, keluarga dan masyarakat perlu dipersiapkan, antara lain apa yang harus dilakukan klien dirumah, apa yang harus dilakukan keluarga untuk membantu 
adaptasi dan bagaimana masyarakat dapat menerima klien apa adanya. Selain itu juga perawat, klien dan keluarga bekerja sama untuk membantu proses adaptasi klien didalam keluarga maupun masyarakat. Perawat dapat membantu kontrak dengan keluarga tentang jadwal Home Visite atau Pasca perawatan di Rumah Sakit. Adapun faktor yang membantu klien untuk tetap dilingkungan keluarga atau di masyarakat adalah pengobatan dan program pasca perawatan di rumah sakit. Dapat disumpulkan, bahwa keberhasilan terapi gangguan jiwa skizofrenia tidak hanya terletak pada terapi obat psikofarmaka dan jenis terapi lainnya, tetapi juga peran serta keluarga dan masyarakat turut menentukan.

Seseorang dengan

Skizofrenia dengan ketidakmampuannya melakukan interaksi sosial tentunya sangat memerlukan adanya dukungan untuk menjadi individu yang lebih kuat dan menghargai diri sendiri sehingga dapat mencapai taraf kesembuhan yang lebih baik dan meningkatkan interaksi sosialnya. Tanpa dukungan keluarga pasien akan sulit sembuh, mengalami perburukan dan sulit untuk bersosialisasi. Uraian tersebut diatas membuat pasien dengan Skizofrenia menarik untuk diteliti. Apalagi sampai saat ini masih banyak masalah yang sering muncul kaitannya dengan perawatan pasien Skizofrenia baik sebelum dan sesudah perawatan di rumah sakit. Penelitian ini dilakukan untuk mengetahui Hubungan antara Dukungan Keluarga dengan Interaksi
Sosial Pada Pasien Skizofrenia Pasca Perawatan di Rumah Sakit.

\section{METODE PENELITIAN}

Desain penelitian ini menggunakan analitik yaitu survei untuk mengetahui hubungan antara sebab akibat dengan jenis Cross Sectional yaitu penelitian yang menekankan pada waktu pengukuran atau observasi data variabel dan hanya satu kali pada satu saat.

Populasi dalam penelitian ini adalah : klien Skizofrenia yang keluar dari Rumah Sakit Jiwa Menur dengan sembuh sosial sebesar 30 orang dan keluarga klien yang tinggal di daerah Surabaya sebesar 30 orang responden. Sampel pada penelitian ini adalah sebagian klien Skizofrenia yang keluar dari Rumah Sakit Jiwa Menur dengan sembuh sosial dan keluarga yang tinggal di daerah Surabaya.

Untuk variabel independent adalah peran keluarga dan variabel dependent adalah tingkat interaksi sosial bermasyarakat. Pengumpulan data dengan pengisian check list, observasi, wawancara dan dianalisis menggunakan SPSS uji statistik Rank Spearman pada tingkat kemaknaan $<0,05$.

Dalam melakukan penelitian, peneliti mengajukan permohonan penelitian kepada Instalasi pendidikan dan ditindak lanjuti dengan permohonan ijin penelitian dari pihak pendidikan kepada pihak Rumah Sakit Jiwa Menur Surabaya. 


\section{HASIL DAN PEMBAHASAN}

Tabel 1 Distribusi Responden Berdasarkan Karakteristik Responden Keluarga dan Klien di RS. Jiwa Menur Surabaya.

\begin{tabular}{lcccc}
\hline \multicolumn{1}{c}{ Karakteristik } & \multicolumn{2}{c}{ Keluarga } & \multicolumn{2}{c}{ Klien } \\
\cline { 2 - 5 } & Jumlah & Persentase(\%) & Jumlah & Persentase(\%) \\
\hline 1. Umur & 4 & & & \\
a. 18-30 tahun & 11 & 39,3 & 19 & 67,9 \\
b. 31-54 tahun & 13 & 46,4 & 5 & 17,9 \\
c. > 55 tahun & & & 4 & 24,3 \\
\hline 2. Jenis Kelamin & 15 & 53,6 & 9 & 32,3 \\
a. Laki-Laki & 13 & 46,4 & 19 & 67,8 \\
b. Perempuan & & & & \\
\hline 3. Pendidikan & 1 & 3,5 & 0 & 0 \\
a. Tidak Sekolah & 10 & 35,8 & 25 & 89,2 \\
b. Dasar & 14 & 50 & 3 & 10,8 \\
c. Menengah & 3 & 10,7 & 0 & 0 \\
d. Tinggi & & & & \\
\hline 4. Pekerjaan & 13 & 46,5 & 24 & 85,8 \\
a. Tidak Bekerja & 1 & 3,5 & 0 & 0 \\
b. PNS & 14 & 50 & 4 & 14,2 \\
c. Swasta & 0 & 0 & 0 & 0 \\
d. ABRI & & & & \\
\hline
\end{tabular}

Data Khusus

1) Karakteristik responden berdasarkan peran keluarga

Tabel 9 Distribusi frekuensi keluarga dalam memenuhi kebutuhan asah, asih, dan asuh pada klien skizofrenia pasca perawatan di RSJ Menur

\begin{tabular}{cccc}
\hline No & Peran keluarga & Frekuensi & Prosentase \\
\hline 1 & Baik & 8 & 28.6 \\
2 & Cukup & 12 & 42.8 \\
3 & Kurang & 8 & 28.6 \\
& & & \\
\hline & Total & 28 & 100 \\
\hline
\end{tabular}

2) Karakteristik responden berdasarkan tingkat interaksi sosial bermasyarakat

Tabel 10 Distribusi frekuensi tingkat interaksi sosial bermasyarakat dalam pemenuhan kebutuhan interaksi, komunikasi, produktivitas pada klien skizofrenia pasca perawatan di RSJ Menur.

\begin{tabular}{llll}
\hline No & Tingkat interaksi sosial & Frekuensi & Prosentase \\
\hline
\end{tabular}




\begin{tabular}{cccc}
\hline 1 & Baik & 9 & 32.1 \\
2 & Cukup & 14 & 50 \\
3 & Kurang & 5 & 17.9 \\
& & & \\
\hline & Total & 28 & 100
\end{tabular}

3) Hubungan antara peran keluarga dengan tingkat interaksi sosial bermasyarakat pada klien skizofrenia pasca perawatan di RSJ Menur, 2011

Tabel 11 Tabulasi silang hubungan antara peran keluarga dengan tingkat interaksi sosial bermasyarakat pada klien skizofrenia pasca perawatan di RSJ Menur

\begin{tabular}{ccccccccc}
\hline \multirow{2}{*}{$\begin{array}{c}\text { Peran } \\
\text { keluarga }\end{array}$} & \multicolumn{4}{c}{ Tingkat Interaksi Sosial Bermasyarakat } & \multicolumn{2}{c}{ Total } \\
\cline { 2 - 6 } & \multicolumn{2}{c}{ Baik } & \multicolumn{2}{c}{ Cukup } & \multicolumn{2}{c}{ Kurang } & & \\
\cline { 2 - 7 } & $\mathrm{N}$ & $\%$ & $\mathrm{~N}$ & $\%$ & $\mathrm{~N}$ & $\%$ & $\mathrm{~N}$ & $\%$ \\
\hline Baik & 5 & 62.5 & 2 & 25 & 1 & 12.5 & 8 & 28.6 \\
Cukup & 3 & 25 & 9 & 75 & 0 & 0 & 12 & 42.8 \\
Kurang & 1 & 12.5 & 3 & 37.5 & 4 & 50 & 8 & 28.6 \\
\hline Total & 9 & 32.1 & 14 & 50 & 5 & 17.9 & 28 & 100 \\
\hline Uji statistik SPSS Rank Spearmen : 0,010 & & & & \\
\hline
\end{tabular}

Dari hasil tabulasi di atas didapatkan dari 8 orang yang memiliki peran keluarga baik sebagian besar $(62,5 \%)$ klien memiliki tingkat interaksi sosial bermasyarakat baik, dan dari 12 orang yang memiliki peran keluarga cukup hanya sebagian kecil (25\%) klien yang memiliki tingkat interaksi sosial bermasyarakat baik. Sedangkan dari 8 orang yang mempunyai peran keluarga kurang setengahnya (50\%) klien mempunyai tingkat interaksi sosial bermasyarakat kurang. Hasil uji Rank Spearman dengan SPSS pada tingkat kemaknaan $<0,05$ dengan nilai $P$ (probability $)=0.010$ dimana lebih kecil dari nilai 0,05 sehingga Ho ditolak yang berarti ada hubungan antara peran keluarga dengan tingkat interaksi sosial bermasyarakat pada klien Skizofrenia pasca perawatan di Rumah Sakit Jiwa Menur.

\section{Pembahasan}

Peran keluarga berguna dalam interaksi sosial klien, dimana klien Skizofrenia sering mendapat manfaat dari peran yang telah dilakukan oleh keluarganya. Berdasarkan tabel 5.9 dari 28 responden menunjukkan bahwa hampir setengahnya $42,8 \%$ (12 responden) peran keluarga yang memenuhi kebutuhan asih, asah, asuh adalah cukup. Hal ini disebabkan adanya faktor yang mempengaruhi, diantaranya adalah latar belakang pendidikan responden yang setengahnya berpendidikan SMA yaitu sebesar 50\% (14 responden). Menurut Effendi (2007) bahwa fungsi biologis yang terdapat pada fungsi keluarga menyebutkan, 
keluarga berfungsi sebagai pemelihara dan merawat anggota keluarga yang memerlukan bantuan, sedangkan fungsi pendidikan, dalam hal ini tugas keluarga adalah mendidik sesuai dengan tingkat perkembangannya dan menyekolahkan untuk memberikan pengetahuan, ketrampilan dan membentuk perilaku sesuai bakat dan minat yang dimilikinya. Karena dengan pendidikan keluarga mampu dan lebih mudah mendapatkan dan menerima informasi dari luar terutama tentang cara mengasuh, menjaga kesehatan khususnya dalam kesehatan mental dan mendidik klien.

Adanya penambahan informasi tentang peranan keluarga pada klien membuat masyarakat dan keluarga sadar akan pentingnya interaksi sosial pada klien Skizofrenia dan akan bersama-sama memperbaiki ke arah yang lebih baik (jiwasehat, 2007). Hasil penelitian didapatkan bahwa hampir setengahnya 46,5\% (13 responden), keluarga tidak atau belum bekerja, maka dapat dilihat bahwa keluarga yang tidak atau belum bekerja, di rumah dapat menemani, mengawasi sekaligus membimbing, mendidik dan mengasuh klien dengan maksimal serta selain itu juga, keluarga bisa menyempatkan untuk memperbanyak menambah informasi dengan membaca atau bertanya kepada orang lain tentang pentingnya peranan keluarga di dalam kesehatan jiwa.

Menurut pendapat Hurlock (1998) dalam Nursalam (2001) semakin cukup umur, tingkat kematangan dan kekuatan seseorang akan lebih matang dalam berfikir dan bekerja, dan dari segi kepercayaan masyarakat, seseorang yang lebih dewasa akan lebih dipercaya dari orang yang belum cukup kedewasaannya. Hal ini sebagai akibat dari pengalaman dan kematangan jiwa. Dari hasil penelitian, hampir setengahnya responden keluarga berumur $>55$ tahun, yaitu sebesar 46,4\% (13 responden), hal ini menunjukkan bahwa umur juga dapat mempengaruhi peran keluarga dalam merawat klien Skizofrenia, karena semakin berumur semakin matang dalam berfikir sehingga dapat lebih bijaksana dalam menghargai klien.

Interaksi sosial bermasyarakat bagi klien dapat membantu dalam meningkatkan hubungan sosial di lingkungan sekitar rumah, sekolah, maupun tempat kerja. Berdasarkan tabel 5.10 dari 28 responden, setengahnya $50 \%$ (14 responden) mempunyai tingkat interaksi sosial cukup. Interaksi sosial adalah hubungan antar manusia dan interaksi positif hanya mungkin terjadi apabila terdapat suasana saling mempercayai, menghargai, dan saling mendukung. Maka dari itu jika klien Skizofrenia mampu berinteraksi secara baik maka akan bermanfaat bagi diri sendiri ataupun orang lain.

Pernyataan yang dikutip dari Kaplan dan Sadock (2010), bahwa perempuan lebih mungkin memiliki fungsi sosial yang lebih baik daripada laki-laki. Hal tersebut berpengaruh dari hasil penelitian, dari 28 responden, sebagian besar klien 67,8\% (19 responden) berjenis kelamin perempuan.

Pekerjaan klien akan menunjang tingkat interaksi sosial, 
karena jika klien sudah mampu untuk bekerja, maka klien juga mampu untuk berinteraksi dengan orang lain secara baik, karena dengan bekerja akan lebih sering berinteraksi dengan orang lain. Tetapi dari hasil penelitian menunjukkan hampir seluruhnya $85,8 \%$ (25 responden) tidak bekerja, kemungkinan hal tersebut dapat menghambat interaksi sosial klien, karena jika dia tidak bekerja maka interaksi sosial juga akan berkurang.

Keluarga sangat berperan terhadap tingkat interaksi sosial klien Skizofrenia, hal tersebut didukung dengan adanya hasil pada tabel 5.11 bahwa peran keluarga dalam memenuhi kebutuhan asah, asih, asuh dengan cukup, diikuti dengan tingkat interaksi klien juga cukup, kemudian dari hasil uji statistik dengan menggunakan SPSS Rank Spearmen perhitungan didapatkan rs $=0.476$, dengan nilai $\mathrm{P}$ (probability) $=0.010$ dimana lebih kecil dari nilai 0,05 sehingga Ho ditolak yang berarti ada hubungan antara peran keluarga dengan tingkat interaksi sosial bermasyarakat pada klien Skizofrenia pasca perawatan di Rumah Sakit Jiwa Menur. Ini menunjukkan bahwa keluarga sangat berperan terhadap tingkat interaksi sosial klien Skizofrenia, sehinga keluarga lebih meningkatkan pengetahuan dan menambah informasi sebanyak-banyaknya tentang interaksi klien serta memperbaiki keadaan yang lebih baik (jiwasehat, 2007)

Menurut Hawari 2005, psikoterapi perilaku adalah upaya umtuk memulihkan kemampuan adaptasi klien agar klien mampu berfungsi kembali secara wajar dalam lingkungannya sehari-hari, di rumah, di sekolah atau kampus, di tempat kerja dan lingkungan sosialnya. Psikoterapi keluarga ini dilakukan untuk melakukan hubungan klien dengan keluarganya. Psikoterapi bertujuan memperkuat fungsi ego agar klien bisa bersosialisasi (RSUD dr. Soetomo, 2002). Teori belajar sosial (social learning theory) perilaku tetap mempertimbangkan suatu timbal balik antara orang dengan lingkungan. Proses kognitif dipandang sebagai faktor penting di dalam memodulasi respon terhadap peristiwa lingkungan (Kaplan dan Sadock 2010).

Untuk meningkatkan interaksi klien, klien dapat mengikuti program konseling sosial dan keahlian serta berdasarkan pada kebutuhan individu, rencana untuk training ketrampilan atau aktifitas rekreasi sosial (Firdaus, 2005). Penelitian yang dilakukan oleh Barton (1970) menyatakan bahwa $50 \%$ dari penderita Skizofrenia kronis yang mengalami progam rehabilitasi dapat kembali produktif dan mampu menyesuaikan diri kembali di keluarga dan masyarakat (Hawari, 2001).

Peran keluarga dapat memenuhi kebutuhan asah, asih, asuh pada klien Skizofrenia, hal ini menunjukkan bahwa keluarga melakukan apa yang diketahui dan apa yang keluarga bisa lakukan misalnya keluarga mengajak untuk kontrol ke rumah sakit jiwa dan mengajari atau memberi bekal pengetahuan tentang keagamaan, akan tetapi yang diperlukan klien Skizofrenia bukanlah itu saja, melainkan dengan melibatkan klien 
dalam mengambil keputusan, memberikan ketrampilan, pendidikan atau melanjutkan sekolah, memberikan aktifitas untuk mengisi waktu luang sehingga klien tidak hanya diam termenung. Hal tersebut memungkinkan klien bisa beradaptasi kembali ke masyarakat dengan kehidupan sosialnya.

Jika keluarga berperan hanya menggantungkan melakukan apa yang hanya diketahui dan apa yang keluarga bisa lakukan, maka klien juga akan melakukan apa yang klien ketahui dan telah dipelajari dari keluarga yang juga tidak maksimal karena kurangnya peran keluarga yang juga tidak maksimal. Diharapkan semua aktifitas klien tidak tergantung kepada keluarga, tetapi terlebih dahulu klien harus mendapatkan bimbingan serta perawatan dari keluarga. Cara meningkatkan produktivitas klien, keluarga disarankan melatih klien dalam melakukan ketrampilan sosial untuk meningkatkan kemampuan sosial, kemampuan memenuhi diri sendiri dan komunikasi interpersonal. Latihan ketrampilan ini melibatkan penggunaan kaset video orang lain dan klien, permainan simulasi (role playing) dalam terapi, dan pekerjaan rumah tentang ketrampilan yang telah dilakukan (Kaplan dan Sadock, 2010)

\begin{tabular}{lrr}
\multicolumn{2}{c}{ Melakukan } & kontinuitas \\
perawatan merupakan hal yang & hal \\
penting yaitu dengan & program \\
berbasis & komunitas, & tingkat \\
perawatan bergantung & pada \\
keparahan dan kesediaan dukungan \\
dari keluarga dan sosial. Program \\
berbasis komunitas ini memberikan \\
layanan komprehensif kepada klien
\end{tabular}

dan keluarga yaitu dengan program day treatment yang meliputi terapi kelompok, pelatihan ketrampilan sosial, pengobatan, sosialisasi dan rekreasi, tetapi pendukung melibatkan sejumlah ahli terapi untuk klien dan keluarga, program psikoedukasi bagi klien, keluarga dan kelompok masyarakat (Isaacs, 2005). Juga melakukan rehabilitasi psikososial dengan menekankan perkembangan ketrampilan yang diperlukan.

Seiring dengan berlalunya waktu dan perkembangan selanjutnya, klien perlahan-lahan akan dapat hidup sesuai dengan kondisi semula sebelum klien sakit karena proses interaksi itu pastinya berjalan secara bertahap mulai dari tidak bisa menjadi bisa meskipun membutuhkan waktu yang lama. Kemandirian klien akan dapat dijalani tanpa bimbingan dari keluarga yang membantu, membimbing, mengasuh secara langsung terhadap perkembangan klien sebelum dan sesudah terjun langsung ke masyarakat.

\section{SIMPULAN}

Berdasarkan hasil penelitian, dapat disimpulkan bahwa sebagai berikut:

1. Sebagian besar peran keluarga terhadap tingkat interaksi sosial bermasyarakat pada klien Skizofrenia pasca perawatan di Rumah Sakit Jiwa Menur berkategori cukup.

2. Sebagian besar tingkat interaksi sosial bermasyarakat pada klien Skizofrenia pasca perawatan di 
Rumah Sakit Jiwa Menur berkategori cukup.

3. Ada hubungan antara peran keluarga dengan tingkat interaksi sosial bermasyarakat pada klien Skizofrenia pasca perawatan di Rumah Sakit Jiwa Menur.

\section{DAFTAR PUSTAKA}

Harold. Kaplan, MD, Benjamin J.Sadock, Md. Jack A Grebb, MD (2009). Sinopsis Psikiatri, Ilmu Pengetahuan Perilaku Psikiatri Klinis. jilid 1

Willy F Maramis. Albert A. Maramis (2009). Catatan ilmu kedokteran Monica Ester (2006). Rencana Askep Psikiatri Marilyn E. Doenges. Mary. C Townsed, Mary Frances Moorhouse. Edisi 3. Jakarta, EGC

Shader (2001). Interaksi Sosial : Kerusakan hubungan sosial yang tajam/menarik diri dari masyarakat. Perilaku eksentrik Komang, A.H. (2006). Asuhan keperawatan keluarga

Marylin M. Friedman Friedman ; Vicky R. Bowden, Elaine G Jones (2010). Buku ajar keperawatan keluarga, Riset, Teori dan Praktik. Edisi 5. Jakarta, EGC

Ann, Isaacs (2005). Keperwatan Kesehatan Jiwa dan Psikiatri. Edisi 3. Jakarta, Penerbit Buku kedokteran EGC.

Hawari, D (2005). Pendekatan Holistik Pada Gangguan Jiwa Skizofrenia. FKUI. Jakarta Izzudin (2007). www.kompas.com. diakses tanggal 20 April 2007
Nursalam (2008). Metodologi Penelitian Ilmu Keperawatan. salemba Mendika. Jakarta Notoatmodjo, S.(2002). Metedologi Penelitian Kesehatan. Rineka Cipta. Jakarta

Poerwadarminta, W.J.S (2001). Kamus Besar Bahasa Indonesia. Edisi 3. Jakarta. Penerbit Departement Pendidikan Dan Kebuadayaan.

Rasmun (2001). Keperawatan Kesehatan Mental Psikiatri Terintregasi Dengan Keluarga. Jakarta. CV. Agung Seto

Saseno (2001). Buku Saku Keperawatan Jiwa, Akper Jiwa Depkes. Magelang

Diane .E.P (2006). Human Development. Edisi 9.

Organisasi.orgkumunitas\&perpustak aanonline.Indonesia. 2010.

Sutarjo A.W. (2009). Pengantar Psikologi Klinis. Edisi Revisi.

Iyus S.(2007). Keperawatan Jiwa. Edisi Revisi

FKUI (2010). Buku Ajar Psikiatri. Jakarta

W. Edith H.P. (2007). www.bali_travelnews.com. Diakses Tanggal 19 April 2007

http://shintaksari.miltiply.com

Diakses Tanggal 19 April 2005

Skizofrenia (2007). www.jiwa sehat.com. Diakses Tanggal 19 April 2007 